\title{
Performance Improvement in Savonius Wind Turbine by Modification of Blade Shape
}

\author{
J. Ramarajan and S. Jayavel ${ }^{\dagger}$ \\ Department of Mechanical Engineering, Indian Institute of Information Technology, Design and \\ Manufacturing Kancheepuram Chennai - 600127, India \\ ${ }^{\dagger}$ Corresponding Author Email: sjv@iiitdm.ac.in
}

(Received December 31, 2020; accepted August 8, 2021)

\begin{abstract}
Wind energy is one of the abundantly available renewable energy resources. Savonius vertical axis wind turbine is better suited for small scale power generation applications with many advantages. The turbine operates independent of wind direction with good starting torque and less noise. But, the power coefficient of the Savonius turbine is less than all other wind turbines. The shape of the turbine blades plays an important role in the performance of the turbine. In this present two-dimensional numerical study, an attempt has been made to improve the turbine performance by considering three types of blade shapes. The complete design details of the proposed new blade shapes are presented. The simulations are carried out using ANSYS Fluent 15.0 with SST $\mathrm{K}-\omega$ turbulence model. The power coefficient of the modified blade is found to have increased by $20 \%$ compared to conventional blade shape. The effect of tip-speed-ratio on power coefficient has also been studied and reported.
\end{abstract}

Keywords: Computational study; Savonius turbine; Wind turbine; Power coefficient; Blade shape; Performance improvement.

\section{NOMENCLATURE}

$\begin{array}{cl}\mathrm{C}_{\mathrm{d}} & \text { drag coefficient } \\ \mathrm{C}_{\mathrm{m}} & \text { moment coefficient } \\ \mathrm{C}_{\mathrm{p}} & \text { power coefficient } \\ d & \text { blade diameter } \\ D & \text { turbine diameter } \\ e & \text { gap-width distance } \\ e / d & \text { gap-width ratio } \\ \mathrm{OD} & \text { outer domain } \\ \mathrm{P}_{\mathrm{S}} & \text { shaft power available in the turbine shaft } \\ \mathrm{P}_{\mathrm{w}} & \text { wind power available in the incoming air }\end{array}$

\section{INTRODUCTION}

The use of fast depleting fossil fuels has many adverse effects on environment. Now the focus is to effectively use clean renewable energy sources so as to reduce the dependence on fossil fuels. Wind energy is one among the renewable energy resources that has high potential for energy production. Horizontal axis wind turbines (HAWT) and vertical axis wind turbines (VAWT) are the two major types based on orientation of the turbine shaft. HAWT is commonly used due to its high power coefficient $\left(C_{p}\right)$. On the other hand, the constraints associated with HAWT are noise pollution, yaw system requirement for orienting the turbine position with respect to the

$\begin{array}{cl}\mathrm{RD} & \text { rotating domain } \\ \mathrm{S} & \text { overlap distance } \\ \mathrm{s} / \mathrm{d} & \text { overlap ratio } \\ \mathrm{T}_{\mathrm{s}} & \text { shaft torque } \\ \mathrm{T}_{\mathrm{W}} & \text { wind torque } \\ \mathrm{V} & \text { wind velocity } \\ \lambda & \text { Tip Speed Ratio (TSR) } \\ \Omega & \text { angular velocity of the rotor } \\ \rho & \text { air density } \\ \theta_{0} & \text { angular position of rotor }\end{array}$

wind direction and installation difficulties. Savonius turbine is a VAWT that can be easily installed on roof tops and suitable for low wind speed, Zhu et al. (2020). Although the effi ciency of Savonius turbine is low, it has more benefits such as (1) it accepts wind from any direction without additional yaw system, (2) starting torque is high so that it rotates even at lower wind speeds, (3) it produces less noise, (4) installation and maintenance cost involved are less in comparison with HAWT and (5) design and fabrication is relatively simple.

Literature comprises of comprehensive research on Savonius turbine for improving its performance. Blackwell et al. (1977) carried out experimental 
investigation on Savonius turbine with fifteen different configurations of the turbine. The parameters considered in the investigation are number of blades, free stream velocity, rotor height, and rotor gap-width ratio. The maximum $C_{p}\left(C_{p}=\right.$ 0.24 ) was reported for the two-blade rotor with gap width ratio in the range of $0.1-0.15$. Alexander and Holownia (1978) also conducted similar investigation with end-plates and shielding. From the experiment, the maximum value of efficiency for two blade rotor was reported as 0.243 that correspond to the configuration with aspect ratio of 4.8 , attached with end plates and shielding. Khan (1978) investigated the performance of Savonius turbine model mounted in wind tunnel and prototype located in open space and reported maximum $C_{p}=0.32$ at $\mathrm{TSR}=1.55$. The maximum power coefficient reported here belongs to a two stage prototype turbine which has a size of $1.72 \mathrm{~m}$ height and $1.22 \mathrm{~m}$ diameter. Khan (1978) showed that the results obtained from prototype and the model wind turbines are not the same. Experimental study on the performance of Savonius turbine by Sivasegaram (1978) showed maximum $C_{p}$ for 2 bladed rotor with blade angle little less than $150^{\circ}$. The author suggested to use $180^{\circ}$ arc angle for multi blade turbines. Effect of introducing the end plates were studied by Jeon et al. (2015) and their results showed increase in turbine performance by $36 \%$ due to increase in frontal area. Zhu et al. (2020) experimentally compared the performance of three small wind turbines namely Savonius VAWT, H-VAWT and HAWT. From the experimental results the authors identified the suitability of Savonius VAWT at lower wind speed.

With the evolution of high performance computing facilities, researchers started numerical studies on various types of wind turbines. Akwa et al. (2012) have studied the effect of overlapping ratio between rotor blades and suggested overlapping ratio equal to 0.15 as optimum. Ferrari et al. (2017) showed the variations in numerical results obtained from $2 \mathrm{D}$ and 3D simulations. The authors have also showed that for $H>1$ there is no change in efficiency, where $H$ is the height of the rotor. The diameter of the rotor is $0.9023 \mathrm{~m}$. In a 2 blade rotor, for half of the rotation one of the blades acts as a driver and the blade is said to be advancing action. For the remaining half of the rotation, the blade has to move against the wind and the blade is said to be in returning motion. At any instant, the net drag is the difference between total drag from the advancing blade and the negative drag due to the returning blade. Ramarajan and Jayavel (2020) have carried out systematic study on the performance of Savonius turbine by varying the parameters such as number of blades, overlap ratio, gap width ratio, blade arc angle and introduced modifications in the rotor blades. An optimum rotor configuration was reported. Researchers have proposed various methods to increase drag on advancing blade and reduce negative drag on returning blade. Ogawa and Yoshida (1986) placed deflecting plates in the upstream side of the rotor to redirect maximum wind on the advancing blade and achieved $24 \%$ increase in $C_{p}$. Modification in the form of slatted technique was introduced by Reupke and Probert (1991). The technique includes opening and closing of blade with respect to a pivoted points. It was showed that the performance of slatted blades was poor compared to conventional rotor as the rotational force dominating the slatted effects. Incorporation of curtains increased drag force acting on the advancing blade, which results in $38.5 \%$ increase in $C_{p}$, Altan et al. (2008). Mohamed et al. (2010) achieved $27 \%$ increase in $C_{p}$ due to the presence of obstacle plates inclined towards advancing rotor. Mohamed et al. (2011) optimized the shape of blade as well as included obstacle plate. Their results showed $30 \%$ overall improvement for the best case. Tartuferi et al. (2015) suggested to use aerofoil type blades for improvement in rotor performance. The attachments such as curtains, diverting plates and deflecting plates are to be mounted in the upstream side of the rotor. The position of these attachments are to be re-oriented as per the wind direction, which imposes operating difficulties.

Modification of the blade shape is another method to improve rotor performance. This method is independent of wind direction and provides benefits such as increasing drag on advancing blade as well as reducing negative drag on returning blade. Thus the literature is rich in the study of blade shape and its effect on rotor performance. Helical type shape modification was investigated by Kamoji et al. (2009) experimentally with and without shaft between the rotors. The results showed that all the helical Savonius rotors have increased positive coefficient of static torque. Capped vents in the blades also improved the rotor performance, Abraham et al. (2012). Kacprzak et al. (2013) investigated rotor performance with different blade shapes such as Bach, elliptical, and conventional semicircular. Their results showed Bach type performs better for TSR in the range, 0.5-1.1. The performance of elliptic blades are better at low TSR in the range, 0.2-0.4. Gad et al. (2014) carried out analysis with modified shape of conventional blades. The new shapes are defined using polynomials developed from three points. Two of the three points are fixed. The third point is varied to obtain different polynomials. The fixed two points are the end points of the conventional blade. The authors reported better performance for one of the modified shapes. Sharma and Sharma (2016) investigated the performance of Savonius turbine with multiple quarter blades and observed a maximum of $13.7 \%$ increase in $C_{p}$. Sanusi et al. (2016) studied the effect of combined elliptical and conventional blade and reported improvement in $C_{p}$ up to $11 \%$ at TSR $=0.79$. Tian et al . (2018) studied the effect of blade thickness and they reported that $C_{p}$ increases by $4.41 \%$. Variation in thickness of the blade shape alters the flow behaviour around the rotor. Increased tip vortices improves the performance of the turbine. Kerikous and Thévenin (2019) modified shape of the blade. Hook shaped blade was reported as optimal shape to divert flow on the advancing blade with $15 \%$ increase in $C_{p}$ at TSR $=1.2$. Alom and Saha (2019) reported improvement in $C_{p}$ for rotor blades with elliptical shape by $20.25 \%$ over semicircular rotor blades. Recently, pivoted blades are analysed experimentally and numerically by Amiri et al. (2019) by varying the aspect ratio and by including end plates. The authors reported that the pivoted wind turbine has 
improved performance. In the present work, comprehensive numerical study has been carried out on the design of blade shape to bring in simultaneous effect of increasing drag on advancing blade and reducing drag on returning blade. The geometry of the proposed blade design are presented. The flow characteristics that leads to the improvement in $C_{p}$ are analysed.

\section{COMPUTATIONAL METHOD- OLOGY}

This section explains the computational techniques adopted in the present study.

\subsection{Governing equations}

The governing equations involved are continuity equation and in-compressible form of NavierStokes equations in $\mathrm{x}$ and $\mathrm{y}$ directions. The equations are given in Eqs. (1\&2).

$\frac{\partial \overline{\mathrm{u}}_{\mathrm{i}}}{\partial \mathrm{x}_{\mathrm{i}}}=0$

$\frac{\partial \bar{u}_{i}}{\partial t}+\frac{\partial}{\partial x_{j}}\left(\overline{u_{i} u_{j}}\right)=-\frac{1}{\rho} \frac{\partial \bar{p}}{\partial x_{i}}+\frac{\partial}{\partial x_{j}}\left(v \frac{\partial \bar{u}_{i}}{\partial x_{j}}-\overline{u_{i}^{\prime} u_{j}^{\prime}}\right)$

In Eq.(2) the mean and fluctuating components are denoted as, $\bar{u}_{i}$ and $u_{i}^{\prime}$ respectively, $\bar{p}$ is the pressure and $v$ is kinematic viscosity, other notations has usual meanings. Solving the Reynolds stress $\overline{u_{i}^{\prime} u_{j}^{\prime}}$ mathematically requires additional equations. In this present study, SST $K-\omega$ turbulent model is used to capture turbulence characteristics in the flow. Equations of $\mathrm{K}$ and $\omega$ are given in Eqs. (3\&4). The generation of turbulent kinetic energy and specific dissipation rate due to mean velocity gradients are denoted as, $G_{K}$ and $G_{\omega}$ respectively. Effective diffusivity of $\mathrm{K}$ and $\omega$ are denoted as $G_{K}$ and $G_{\omega}$, dissipation $\mathrm{K}$ and $\omega$ due to turbulence are denoted as $Y_{k}$ and $Y_{\omega}$, cross diffusion is represented as $D_{\omega}$, source terms corresponding to $\mathrm{K}$ and $\omega$ are denoted as $S_{k}$ and $S_{\omega}$

$\frac{\partial}{\partial t}(\rho \mathrm{k})+\frac{\partial}{\partial \mathrm{x}_{\mathrm{i}}}\left(\rho \mathrm{ku}_{\mathrm{i}}\right)=\frac{\partial}{\partial \mathrm{x}_{\mathrm{j}}}\left(\Gamma_{\mathrm{k}} \frac{\partial \mathrm{k}}{\partial \mathrm{x}_{\mathrm{j}}}\right)+\mathrm{G}_{\mathrm{k}}-\mathrm{Y}_{\mathrm{k}}+\mathrm{S}_{\mathrm{k}}$

$\frac{\partial}{\partial \mathrm{t}}(\rho \omega)+\frac{\partial}{\partial \mathrm{x}_{\mathrm{i}}}\left(\rho \omega \mathrm{u}_{\mathrm{i}}\right)=\frac{\partial}{\partial \mathrm{x}_{\mathrm{j}}}\left(\Gamma_{\omega} \frac{\partial \omega}{\partial \mathrm{x}_{\mathrm{j}}}\right)$

$+\mathrm{G}_{\omega}-\mathrm{Y}_{\omega}+\mathrm{D}_{\omega}+\mathrm{S}_{\omega}$

\subsection{Modelling}

The blades of Savonius turbine is shown in Fig.1(a). The flow variation along the height of the blades is assumed to be negligible. Therefore, in this present study two-dimensional analysis has been carried out. The two-dimensional representation of Savonius turbine is shown in Fig.1(b). According to the flow direction given, the turbine will rotate in counter clockwise direction. In Fig.1(b) the lower blade of the turbine presently in advancing action and the upper blade is in returning action. During advancing action, the blade will assist the rotation of the turbine, but during returning action the blade has to resist the rotation of the turbine

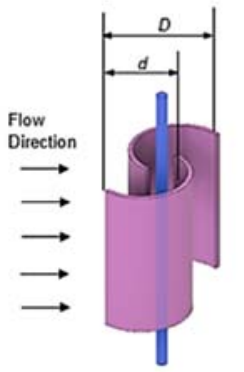

(a)

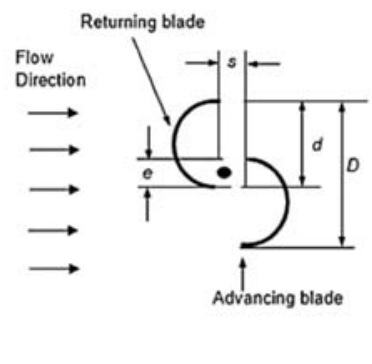

(b)
Fig. 1. Savonius wind turbine with two blades (a) 3-D model (b) 2-D representation.

Computational domain has been created with two sub-domains namely, stationary outer domain, and inner rotating domain. The size of the rectangular

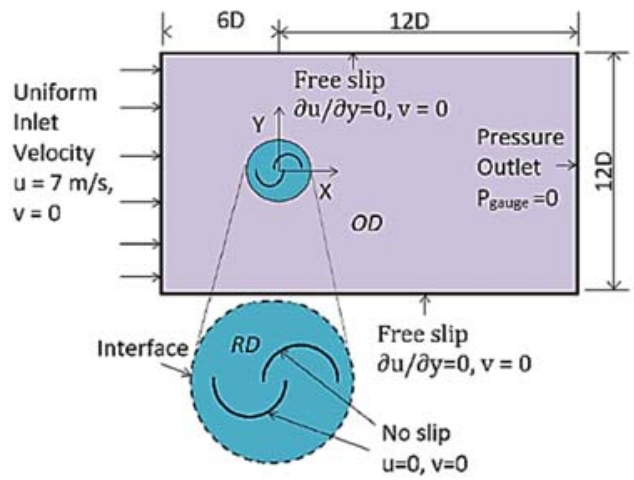

Fig. 2. Computational D \domain.

outer domain is $12 D \times 18 D$, where $D$ is diameter of the rotor. The diameter of the circular inner domain is $1.2 D$. The center of inner rotating domain is placed at a distance of $6 D$ from the side walls and from the inlet as shown in Fig.2. The specification of the rotor is summarized in Table 1.The specifications of the rotor are taken as recommended by Blackwell et al. (1977).

\subsection{Boundary conditions}

Solving the governing equations needs the boundary conditions, following boundary conditions are applied at the respective boundaries. Inlet of the computational domain is imposed with uniform inlet velocity boundary condition $(u=7 \mathrm{~m} / \mathrm{s}$ and $v=0)$. Pressure outlet is set on the outlet boundary. The interface boundary condition is imposed between the outer and the rotating domains. No-slip wall boundary condition $(u=0, v=0)$ is imposed at blade 
surfaces. Free slip condition is imposed at sidewalls of the domain.

Table 1 Specifications of the rotor

\begin{tabular}{|c|c|}
\hline Parameters & Dimension \\
\hline Number of blades & 2 \\
\hline Blade diameter (d) & $500 \mathrm{~mm}$ \\
\hline Turbine diameter (D) & $975 \mathrm{~mm}$ \\
\hline Blade thickness (t) & $2 \mathrm{~mm}$ \\
\hline Gap width ratio (e/d) & 0.15 \\
\hline Overlap ratio (s/d) & 0 \\
\hline Blade arc angle & $180^{\circ}$ \\
\hline
\end{tabular}

\subsection{Meshing}

The computational domain is meshed using ANSYS Mesh. The outer domain is meshed using structured grid. The meshed domain is shown in Fig. 3. The rotating domain is meshed with unstructured grids as shown in Figs. 3(b, c \& d). At the interface between outer and rotating domains, equal sizes of grids are maintained as shown in 3(e). To capture steep gradients in the flow field near the blade walls, first layer distance is maintained as $0.04 \mathrm{~mm}$ and the growth rate is 1.2 up to 15 layers as shown in $3(\mathrm{f})$. To fit the linear velocity profile in the first layer, nondimensional distance, $y^{+}$value is maintained as $\approx 1$.

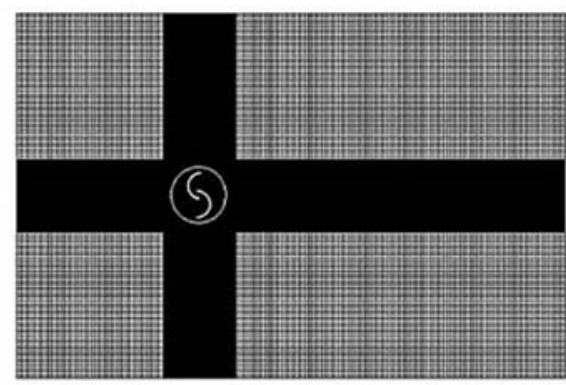

(a)

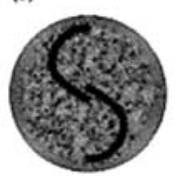

(b)

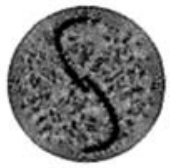

(c)

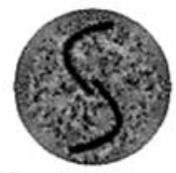

(d)

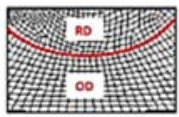

(e)

(f)

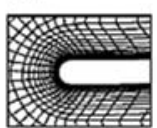

Fig. 3. Meshed computational domain (a) full domain $(b, c, d)$ rotating domains with different blade shapes (e) interface between OD and RD (f) mesh near tip of the blade.

\subsection{Grid Independence Study}

Grid independence study has been carried out to conduct simulations within a reasonable time and with good accuracy. Initially, the study is started with an element size of $200 \mathrm{~mm}$. Later, the size of the elements are varied systematically to study the effect if grid size on moment coefficient at a tip speed ratio of 0.8 . The results are presented in Table 2. The optimum grid number has been identified as 130905 .

Table 2 Summary of grid independence study

\begin{tabular}{|c|c|c|}
\hline $\begin{array}{c}\text { No. of } \\
\text { Elements }\end{array}$ & Averaged $C_{m}$ & \% Deviation \\
\hline 74146 & 0.2635 & - \\
\hline 92162 & 0.2828 & 7.32 \\
\hline 107250 & 0.2715 & 3.99 \\
\hline 130905 & 0.2765 & 1.84 \\
\hline 145104 & 0.2754 & 0.39 \\
\hline
\end{tabular}

\subsection{Solution methodology}

Control volume based ANSYS Fluent solver is used in this present numerical study. SIMPLE algorithm is used for velocity and pressure coupling. The second-order upwind scheme is used for momentum, turbulent kinetic energy $(\mathrm{K})$, and specific dissipation rate $(\omega)$. The convergence criteria of $10^{-6}$ is set for continuity equation and for velocities, $\mathrm{K}$ and $\omega$ the convergence criteria is $10^{-5}$. Unsteady, pressure-based 2-D numerical simulations are carried out up to 10 s with a time step size of $0.005 \mathrm{~s}$.

\section{SHAPE MODIFICATION}

The shape of the Savonius blades is playing an important role in power extraction from the wind. Savonius blades during returning action, it has to resist the rotation of the rotor, the rear shape of the blade can be modified to have reduced drag during returning action, so that the performance can be improved. Since the rear shape of the blade is convex in conventional shape blade, at the time returning action, a part of the air is getting diverted away from the rotor, remaining part is directed towards the advancing blade. The modified blades are aimed to increase the diversion of air away from the rotor and also to increase the flow towards the advancing blade. In this present study, open splines are used to define the geometry of the blade. These open splines are alters the drag force acting on the blades of the turbine, such that the performance of the turbine improves. Blades of four different shapes namely, (1) conventional semi-circular, (2) half-modified, (3) three-fourth modified and (4) fully modified are considered in the present study to improve the turbine performance. It is to be noted that in each case, both the returning and the advancing blades are identical. The performance of the rotor with modified shapes are compared with conventional semi-circular turbine blades.

1. Conventional blade: The conventional turbine blade shape is shown in Fig.4.The beginning and the end points of the advancing blade are $(0,37.5)$ 
and $(0,-462.5)$, respectively. The radius of the semicircular blade is $250 \mathrm{~mm}$. The angle of the rotor blade is $180^{\circ}$. At any position of the rotor, towards the length (L) of the blade, the radial distance (R) can be found by the Eq.(5). For the The error percentage with Blackwell et al. (1977) is ranges in between $0-4.2 \%$

$$
\mathrm{R}=\sqrt{250^{2}-(\mathrm{L}+212.5)^{2}}
$$

2. Half-modified blade: The shape of the halfmodified blade is shown in Fig.4 . The blade is partly (half) modified using a spline. Three points are given as input to define the open spline, where the first and third points of the open spline are the beginning and the end points of the conventional shape, i.e., $(0,37.5)$ and $(0,-462.5)$, respectively. The second point of the spline is placed at $(250,-$ 212.5), which is the mid location of the conventional shape. The blade shape is constructed using Ansys Design Modeler. The first part of the blade is defined by the open spline with end points $(0,37.5)$ and $(250,-212.5)$. The remaining part of the advancing blade is same conventional blade. the modified half length open spline is shown in dotted line with colour red. Open spline blade profile Eq. (6) is applicable for $0^{\circ} \leq \theta_{1} \leq 90^{\circ}$. For the remaining portion of the blade i.e., for $90^{\circ} \leq \theta_{2} \leq 180^{\circ}$, the blade profile is given in Eq.(5).

$R=-0.00374 L^{2}-1.657 \mathrm{~L}+67.478$

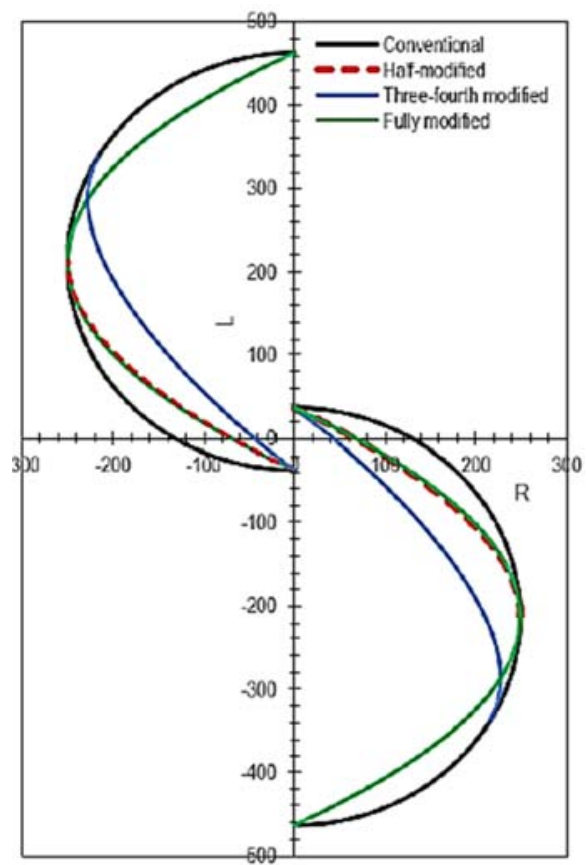

Fig. 4. Blade shapes considered in the present study (a) conventional semi-circular (b) halfmodified (c) three-fourth modified (d) fully modified.
3. Three-fourth modified blade: The shape of the three-fourth modified blade is shown in blue colour line in Fig.4 . The first part of the blade is defined by an open spline and the remaining part is circular arc. The first and third points of the open spline are the beginning and the end points of the conventional shape, i.e., $(0,37.5)$ and $(0,-462.5)$, respectively. The second point of the spline is placed at $(216.5,-337.5)$ which is three fourth of its overall length, so that $\theta_{1}=135^{\circ}$ and $\theta_{2}=45^{\circ}$. The open spline takes the equation form as given in Eq. (7). The second part of the advancing blade indicated as $\mathrm{V}$ is defined by Eq. (5)

$$
\mathrm{R}=2.42 \times 10^{-6} \mathrm{~L}^{3}-7.92 \times 10^{-4} \mathrm{~L}^{2}-1.07 \mathrm{~L}+40.11
$$

d. Fully modified blade: This shape is generated using an open spline with the following points $(0$, $37.5),(250,-212.5)$ and $(0,-462.5)$. The resulting shape of the blade is shown in green line in Fig.4. The shape of the blade defined by the following Eq.(8) which is a parabolic equation.

$$
\mathrm{R}=-0.004 \mathrm{~L}^{2}-1.7 \mathrm{~L}+69.375
$$

In all the four shapes considered here, the first and last point of the blades are maintained same. Hence the diameter of the blade is same for all the shapes.

\section{Results AND Discussions}

Numerical simulations are carried out for sufficiently long time, so that the dynamic stability is obtained. The instantaneous drag force, drag coefficient and moment coefficient are captured with respect to each time-step during the simulation. After three full rotation of the rotor, the periodicity is observed in drag force, drag and moment coefficients. However, the rotor is allowed to rotate for a flow-time of $10 \mathrm{~s}$ with a time step of $0.005 \mathrm{~s}$ to ensure dynamic stability. As mentioned previously, the residuals for convergence criteria was set as $10^{-6}$ for continuity equation. For velocities, and for $\mathrm{K}$ and $\omega$ the value was set as $10^{-5}$. With the available computational facility, each simulation had taken 6-8 hrs to reach the flow time of $10 \mathrm{~s}$. Then the results were taken and used for analysis. Moment coefficient is given in Eq. (9) and it is defined as ratio of torque produced by the turbine to the input energy from air in the form of torque. The power coefficient (Eq.10) is defined as the ratio of output power generated by the turbine to the input power available in the air. The averaged value of $C_{m}$ for the last two revolutions of the rotor is used for further calculations. The value of $C_{p}$ is calculated for various TSR using the relation given in Eq. (11).

$$
\begin{aligned}
& \mathrm{C}_{\mathrm{m}}=\frac{\mathrm{T}_{\mathrm{s}}}{\mathrm{T}_{\mathrm{w}}}=\frac{\mathrm{T}_{\mathrm{s}}}{\frac{1}{2} \rho A V^{2} \mathrm{R}} \\
& \mathrm{C}_{\mathrm{p}}=\frac{\mathrm{P}_{\mathrm{s}}}{\mathrm{P}_{\mathrm{w}}}=\frac{\mathrm{T}_{\mathrm{s}} \omega}{\frac{1}{2} \rho A V^{3}}
\end{aligned}
$$




$$
\text { lambda }=\frac{\mathrm{C}_{\mathrm{p}}}{\mathrm{C}_{\mathrm{m}}}=\frac{\mathrm{R} \omega}{\mathrm{V}}
$$

\subsection{Validation}

Simulations are conducted for various tip speed ratios. $C_{p}$ attains a maximum value for $\mathrm{TSR} \approx 0.8$. The present results are validated with the existing experimental literature of Blackwell et al. (1977) and numerical results of Akwa et al. (2012). The results are matching well with the literature, as shown in Fig.5. For the TSR $\leq 0.9$ the error percentage with Blackwell et al. (1977) in the range of 0-4.2.

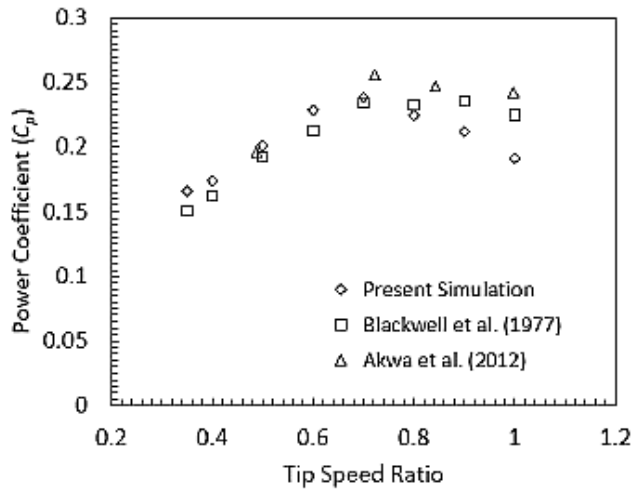

Fig. 5. Effect of TSR on $C_{p}$ (conventional shape).

The shape of the blade primarily plays a vital role in the performance of VAWT. During rotation, the blade's concavity helps for advancing action to be strongest. During returning action, carefully designed convex shape of the blade offers minimum drag. The $C_{p}$ results obtained from the the modified blades are discussed in this section. The results are shown in Fig. 6 . The results showed improved performance for three-fourth modified blade at all tip speed ratios. The performance of fully modified and half-modified blades are more or less same as the conventional blades.

At an angular position of $90^{\circ}$ of the rotor position, pressure contours and streamline plots are shown in Figs. 7 \& 8, respectively. Two distinct flow characteristics are observed from Figs. $7 \&$ 8. The first observation is the location on the blade at which the maximum pressure acts. Obviously, it is the stagnation point on the blade surface where the the maximum pressure is observed. This location depends on the blade shape. The effect of this location on $C_{p}$ is as follows: The increase in the distance between the location and the axis of the rotor leads to increase in the rotor torque. The second observation is the flow bifurcation that depends on the blade shape. The wind stream that strikes on the surface of the returning blade is bifurcated and a part of the stream is thrown outward from the rotor. Another part of the stream is diverted towards the advancing blade. Favourable combination of these effects is seen in three-fourth modified blade shape.The stagnation point with respect to the returning blade is at mid-point for conventional semi-

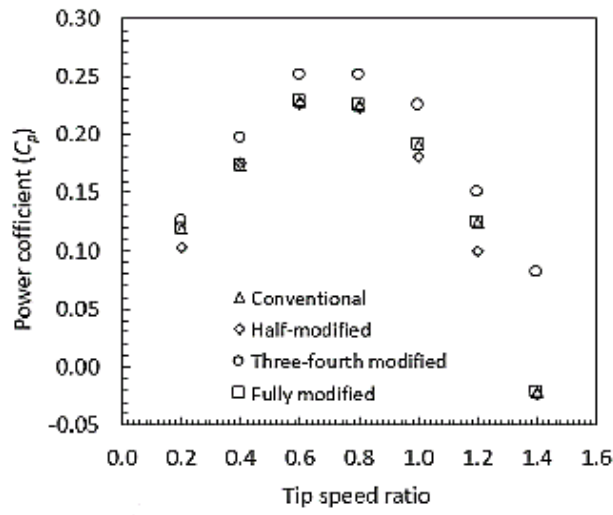

Fig. 6. Effect of blade shapes on Cp.

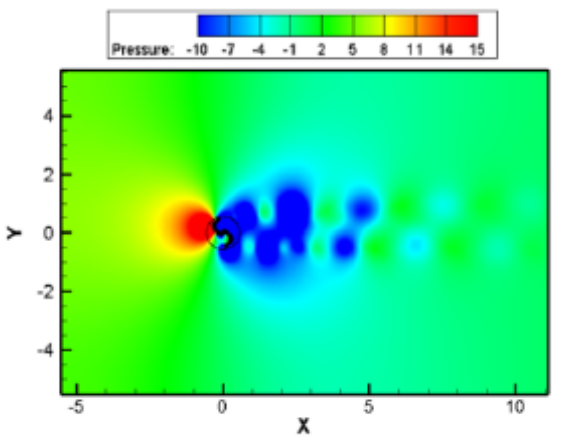

(a)

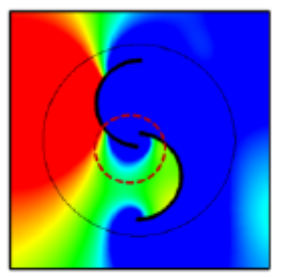

(b)

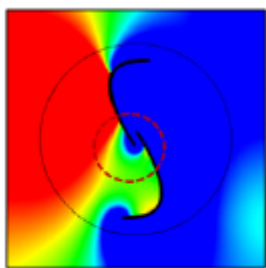

(d)

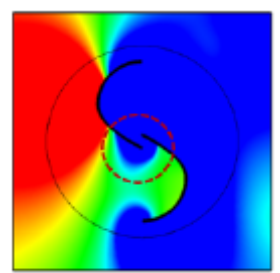

(c)

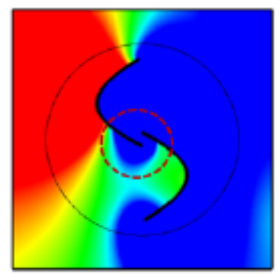

(e)
Fig. 7. Pressure (Pa) contours at $90^{\circ}$ position of the rotor $(\lambda=0.8)$ (a) over the entire domain (b) conventional semi-circular (c) half-modified (d) three-fourth modified (e) fully modified.

circular, halfmodified and fully modified blade shapes. This leads to $\leq 50 \%$ diversion of air stream towards the advancing blade. For three-fourth modified blade shape, the stagnation point is shifted in such a way that $>50 \%$ diversion of air stream towards the advancing blade is made possible.

The rotor's drag coefficient variation for one 
complete revolution at the tip speed ratio of 0.8 is compared in Fig. 9. This $C_{d}$ variation represented is the average value obtained from both blades. The rotor has a maximum $C_{d}$ once during the driver mode and later during the driven mode. That is, the maximum $C_{d}$ occurs twice in a rotation. Variation in the shape of the blade alters the rotor's ability to receive drag force from the incoming air. There is no much variation in the average value of $C_{d}$ for the rotor with conventional semi-circular, half-modified and fully modified blade shapes. But as shown in Fig. 9, the continuous line shows considerable changes in $C_{d}$ variation in the drag coefficient for three-fourth modified blade shape.
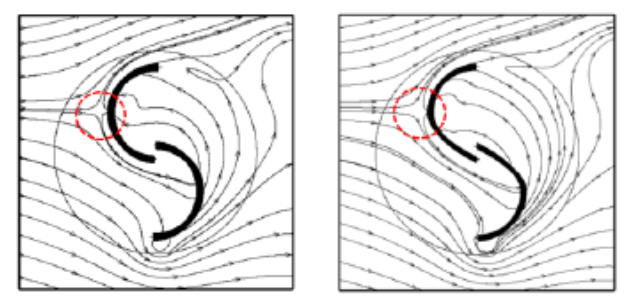

(a)

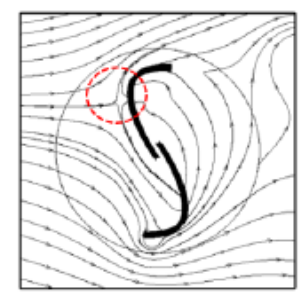

(c)

(b)

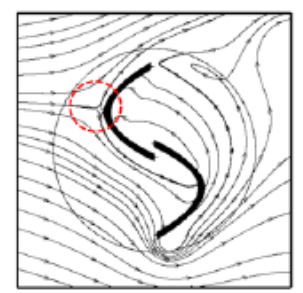

(d)

Fig. 8. Streamlines near the rotor $(\lambda=0.8)$ (a) conventional semi-circular (b) half-modified (c) three fourth modified (d) fully modified.

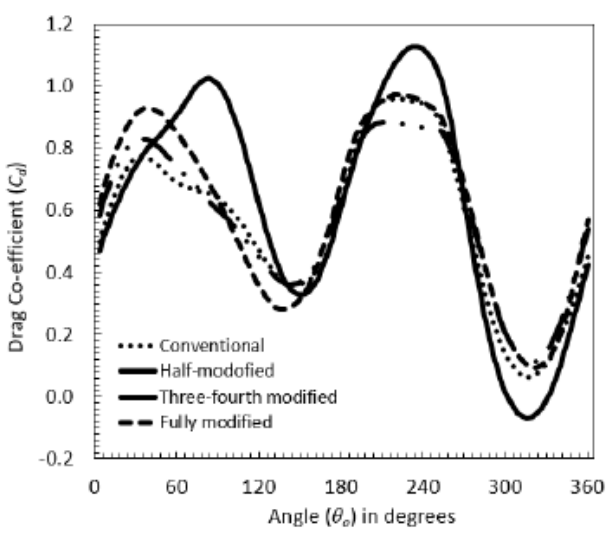

Fig. 9. Variation in drag coefficient $(\mathrm{Cd})$ for one complete rotation of the $\operatorname{rotor}(\lambda=0.8)$.

The drag force variation on a single blade of the conventional and three-fourth modified blades are compared in Fig.10. It is observed that the area enclosed is more on positive side of the loop for

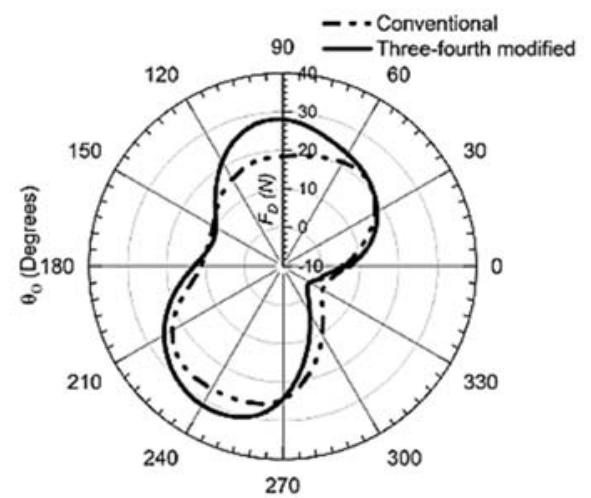

Fig. 10. Comparison of variation in drag force on one of the blades.

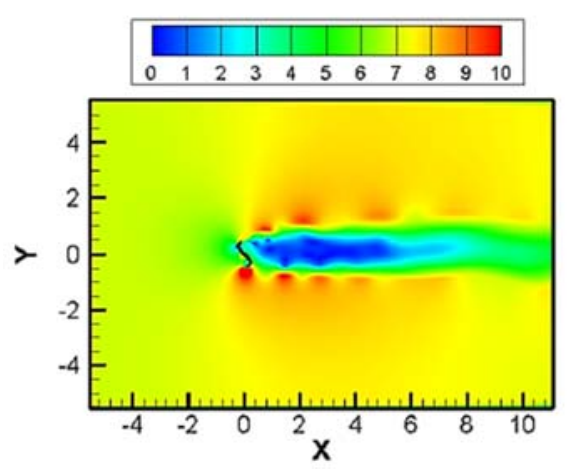

Fig. 11. Velocity magnitude $(\mathrm{m} / \mathrm{s})$ variation around three-fourth modified blade at $90^{\circ}$ angular position $(\lambda=0.8)$.

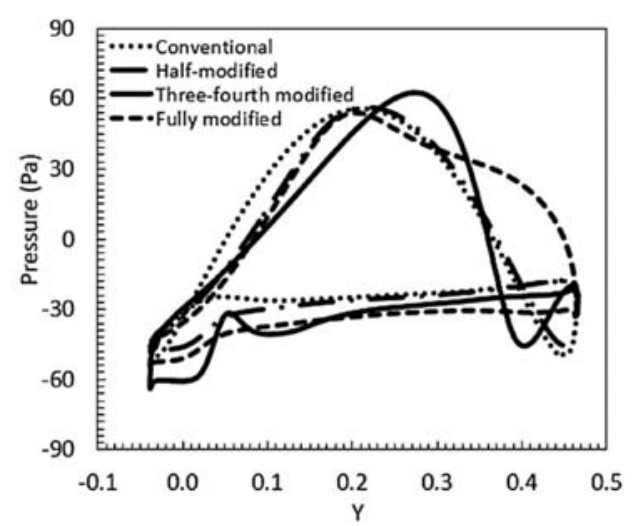

Fig. 12. Comparison of variation in pressure on the surface of returning blade at $90^{\circ}$ angular position

three-fourth modified blade shape compared to the conventional blade. This shows the performance improvement due to shape modification. Velocity magnitude variation around the rotor of three fourth modified blade is shown in Fig. 11 for tip speed ratio of 0.8 at an angular position of $90^{\circ}$. The maximum pressure drop across the rotor occurs at this angular 
poition of the rotor. The stagnation point occurs at this time period, the location of the stagnation point from the origin of the turbine is measured as $267.5 \mathrm{~mm}$, whereas the effective radius of the blade is $231.25 \mathrm{~mm}$. As discussed earlier, a shift in maximum force location improves the performance of the rotor. The pressure variations on the returning blade surfaces for all the four shapes are compared in Fig. 12. The angular position of the rotor is at $90^{\circ}$. Here the maximum pressure for conventional semicircular, half-modified and fully modified blade shapes occurs at a mid-point of the blades. But in the case of three-fourth modified blade shape, the stagnation point is shifted as discussed earlier. Therefore, as we aimed to divert the flow away from the rotor and also towards the advancing blade takesplace. The asymmetric behaviour in pressure force can be observed from the Fig. 12, whereas other blades are having close to symmetric behaviour. Throughout the length of the blade less pressure compared to other shapes is found in the three-fourth modified blade while returning.

\section{Conclusions}

Numerical analysis of Savonius type vertical axis wind turbine has been carried out for four different configurations. Control volume based commercial ANSYS Fluent solver with SST K- $\omega$ turbulence model is used for simulations. The modified shapes are based on spline curves. The blades are either partially modified or fully modified and its effect on rotor performance is studied. The performance analysis is carried out on these modified blades and compared with conventional semi-circular blade shape. The blade with three-fourth modification is found to have improved performance compared to all other shapes. Improvement in $C_{p}$ depends on TSR. The percentage increase in $C_{p}$ varies from $4 \%$ to $20 \%$ for three-fourth modified shape.

\section{REFERENCES}

Abraham, J., B. Plourde, G. Mowry, W. Minkowycz and E. Sparrow (2012). Summary of savonius wind turbine development and future applications for small-scale power generation. Journal of Renewable and Sustainable Energy 4(4), 042703.

Akwa, J. V., G. A. da Silva Júnior and A. P. Petry (2012). Discussion on the verification of the overlap ratio influence on performance coefficients of a savonius wind rotor using computational fluid dynamics. Renewable Energy 38(1), 141-149.

Alexander, A. and B. Holownia (1978). Wind tunnel tests on a savonius rotor. Journal of Wind Engineering and Industrial Aerodynamics 3(4), 343-351.

Alom, N. and U. K. Saha (2019). Influence of blade profiles on savonius rotor performance: Numerical simulation and experimental validation. Energy Conversion and Management 186, 267-277.
Altan, B. D., M. Atılgan and A. Özdamar (2008). An experimental study on improvement of a savonius rotor performance with curtaining. Experimental thermal and fluid science 32(8), 1673-1678.

Amiri, M., M. Kahrom and A. R. Teymourtash (2019). Aerodynamic analysis of a three-bladed pivoted savonius wind turbine: Wind tunnel testing and numerical simulation. Journal of Applied Fluid Mechanics 12(3), 819-829.

Blackwell, B. F., L. V. Feltz and R. E. Sheldahl (1977). Wind tunnel performance data for twoand three-bucket Savonius rotors. Sandia Laboratories Albuquerque, New Mexico.

Ferrari, G., D. Federici, P. Schito, F. Inzoli and R. Mereu (2017). Cfd study of savonius wind turbine: $3 \mathrm{~d}$ model validation and parametric analysis. Renewable Energy 105, 722-734.

Gad, H., A. Abd El-Hamid, W. El-Askary and M. Nasef (2014). A new design of savonius wind turbine: numerical study. CFD Letters 6(4), 144 158.

Jeon, K. S., J. I. Jeong, J.-K. Pan and K.-W. Ryu (2015). Effects of end plates with various shapes and sizes on helical savonius wind turbines. Renewable Energy 79, 167-176.

Kacprzak, K., G. Liskiewicz, and K. Sobczak (2013). Numerical investigation of conventional and modified savonius wind turbines. Renewable Energy 60, 578-585.

Kamoji, M., S. Kedare and S. Prabhu (2009). Performance tests on helical savonius rotors. Renewable Energy 34(3), 521-529.

Kerikous, E. and D. Thévenin (2019). Optimal shape of thick blades for a hydraulic savonius turbine. Renewable Energy 134, 629- 638.

Khan, M. H. (1978). Model and prototype performance characteristics of savonius rotor windmill. Wind Engineering, 75-85.

Mohamed, M., G. Janiga, E. Pap and D. Thévenin (2010). Optimization of savonius turbines using an obstacle shielding the returning blade. Renewable Energy 35(11), 2618-2626.

Mohamed, M., G. Janiga, E.Pap and D. Thévenin (2011). Optimal blade shape of a modified savonius turbine using an obstacle shielding the returning blade. Energy Conversion and Management 52(1), 236- 242.

Ogawa, T. and H. Yoshida (1986). The effects of a deflecting plate and rotor end plates on performances of savonius-type wind turbine. Bulletin of JSME 29(253), 2115-2121.

Ramarajan, J. and S. Jayavel (2020). Numerical study of the effect of geometry and operating parameters on the performance of savonius vertical axis wind turbine. Current Science 119(12), 1927-1938.

Reupke, P. and S. Probert (1991). Slatted-blade savonius wind-rotors. Applied Energy 40(1), 
J. Ramarajan and S. Jayavel / JAFM, Vol. 15, No. 1, pp. 99-107, 2022.

\section{$65-75$.}

Sanusi, A., S. Soeparman, S. Wahyudi, and L. Yuliati (2016). Experimental study of combined blade savonius wind turbine. International Journal of Renewable Energy Research (IJRER) 6(2), 614-619.

Sharma, S. and R. K. Sharma (2016). Performance improvement of savonius rotor using multiple quarter blades-a cfd investigation. Energy Conversion and Management 127, 43-54.

Sivasegaram, S. (1978). An experimental investigation of a class of resistance-type, direction-independent wind turbines. Energy 3(1), 23-30.
Tartuferi, M., V. D'Alessandro, S. Montelpare and R. Ricci (2015). Enhancement of savonius wind rotor aerodynamic performance: a computational study of new blade shapes and curtain systems. Energy 79, 371-384.

Tian, W., Z. Mao, B. Zhang and Y. Li (2018). Shape optimization of a savonius wind rotor with different convex and concave sides. Renewable energy 117, 287-299.

Zhu, J., L. Zhang, Q. Qu and P. Liu (2020). Experimental investigation of aerodynamic characteristics for three typical micro wind turbines at low reynolds number. Journal of Applied Fluid Mechanics 13(4). 